\title{
Smoking, Smoking Cessation, and Risk of Mortality in a Japanese Working Population - Japan Epidemiology Collaboration on Occupational Health Study -
}

\author{
Shamima Akter, PhD; Tohru Nakagawa, MD, PhD; Toru Honda, MD; \\ Shuichiro Yamamoto, MD, PhD; Keisuke Kuwahara, PhD; Hiroko Okazaki, MD, PhD; \\ Huanhuan Hu, PhD; Teppei Imai, MD, PhD; Akiko Nishihara, MD; Toshiaki Miyamoto, MD, PhD; \\ Naoko Sasaki, MD; Takayuki Ogasawara, MD; Akihiko Uehara, MD, PhD; \\ Makoto Yamamoto, MD, PhD; Taizo Murakami, MD; Makiko Shimizu, MD; Masafumi Eguchi, MD; \\ Takeshi Kochi, MD, PhD; Ai Hori, MD, PhD; Satsue Nagahama, MD; Kentaro Tomita, MD; \\ Maki Konishi; Ikuko Kashino, PhD; Akiko Nanri, PhD; Isamu Kabe, MD, PhD; \\ Tetsuya Mizoue, MD, PhD; Naoki Kunugita, MD, PhD; Seitaro Dohi, MD, PhD \\ for the Japan Epidemiology Collaboration on Occupational Health Study Group
}

Background: The effect of smoking on mortality in working-age adults remains unclear. Accordingly, we compared the effects of cigarette smoking and smoking cessation on total and cause-specific mortality in a Japanese working population.

\begin{abstract}
Methods and Results: This study included 79,114 Japanese workers aged 20-85 years who participated in the Japan Epidemiology Collaboration on Occupational Health Study. Deaths and causes of death were identified from death certificates, sick leave documents, family confirmation, and other sources. Hazard ratios (HRs) and 95\% confidence intervals (Cls) were estimated via Cox proportional hazards regression. During a maximum 6-year follow-up, there were 252 deaths in total. Multivariable-adjusted HRs (95\% Cls) for total mortality, cardiovascular disease (CVD) mortality, and tobacco-related cancer mortality were 1.49 (1.10-2.01), 1.79 (0.99-3.24), and 1.80 (1.02-3.19), respectively, in current vs. never smokers. Among current smokers, the risks of total, tobacco-related cancer, and CVD mortality increased with increasing cigarette consumption $\left(P_{\text {trend }}<0.05\right.$ for all). Compared with never smokers, former smokers who quit $<5$ and $\geq 5$ years before baseline had HRs (95\% Cls) for total mortality of $1.80(1.00-3.25)$ and $1.02(0.57-1.82)$, respectively.
\end{abstract}

Conclusions: In this cohort of workers, cigarette smoking was associated with increased risk of death from all and specific causes (including CVD and tobacco-related cancer), although these risks diminished 5 years after smoking cessation.

Key Words: All-cause mortality; Cancer mortality; Cardiovascular disease mortality; Occupational health; Smoking

$\mathbf{T}$ obacco smoking is a leading risk factor for diseases worldwide. An extensive body of literature has consistently shown that smoking increases the risk of mortality. ${ }^{\mathbf{1} 2}$ Globally, tobacco smoking has been estimated to cause 5 million deaths per year. ${ }^{3}$ As in other

Editorial p 2941

countries, smoking is strongly associated with mortality in Japan. According to a pooled analysis of 3 large-scale

Received April 5, 2018; revised manuscript received July 19, 2018; accepted July 31, 2018; released online September 12 , 2018 Time for primary review: 32 days

Department of Epidemiology and Prevention, National Center for Global Health and Medicine, Tokyo (S.A., K.K., H.H., M.K., I. Kashino, T. Mizoue); Hitachi, Ltd., Ibaraki (T.N., T.H., S.Y.); Teikyo University Graduate School of Public Health, Tokyo (K.K.); Mitsui Chemicals , Inc., Tokyo (H.O., S.D.); Azbil Corporation, Tokyo (T.I., A. Nishihara); Nippon Steel \& Sumitomo Metal Corporation Kimitsu Works, Chiba (T. Miyamoto); Mitsubishi Fuso Truck and Bus Corporation, Kanagawa (N.S., T.O.); Seijinkai Shizunai Hospital, Hokkaido (A.U.); YAMAHA CORPORATION, Shizuoka (M.Y.); Mizue Medical Clinic, Keihin Occupational Health Center, Kanagawa (T. Murakami, M.S.); Furukawa Electric Co., Ltd., Tokyo (M.E., T.K., I. Kabe); Department of Global Public Health, University of Tsukuba, Ibaraki (A.H.); All Japan Labour Welfare Foundation, Tokyo (S.N.); Mitsubishi Plastics, Inc., Tokyo (K.T.); Department of Food and Health Sciences, Fukuoka Women's University, Fukuoka (A. Nanri); and National Institute of Public Health, Saitama (N.K.), Japan

Mailing address: Shamima Akter, PhD, Department of Epidemiology and Prevention, Center for Clinical Sciences, National Center for Global Health and Medicine, 1-21-1 Toyama, Shinjuku-ku, Tokyo 162-8655, Japan. E-mail: samimarub@yahoo.com

ISSN-1346-9843 All rights are reserved to the Japanese Circulation Society. For permissions, please e-mail: cj@j-circ.or.jp 


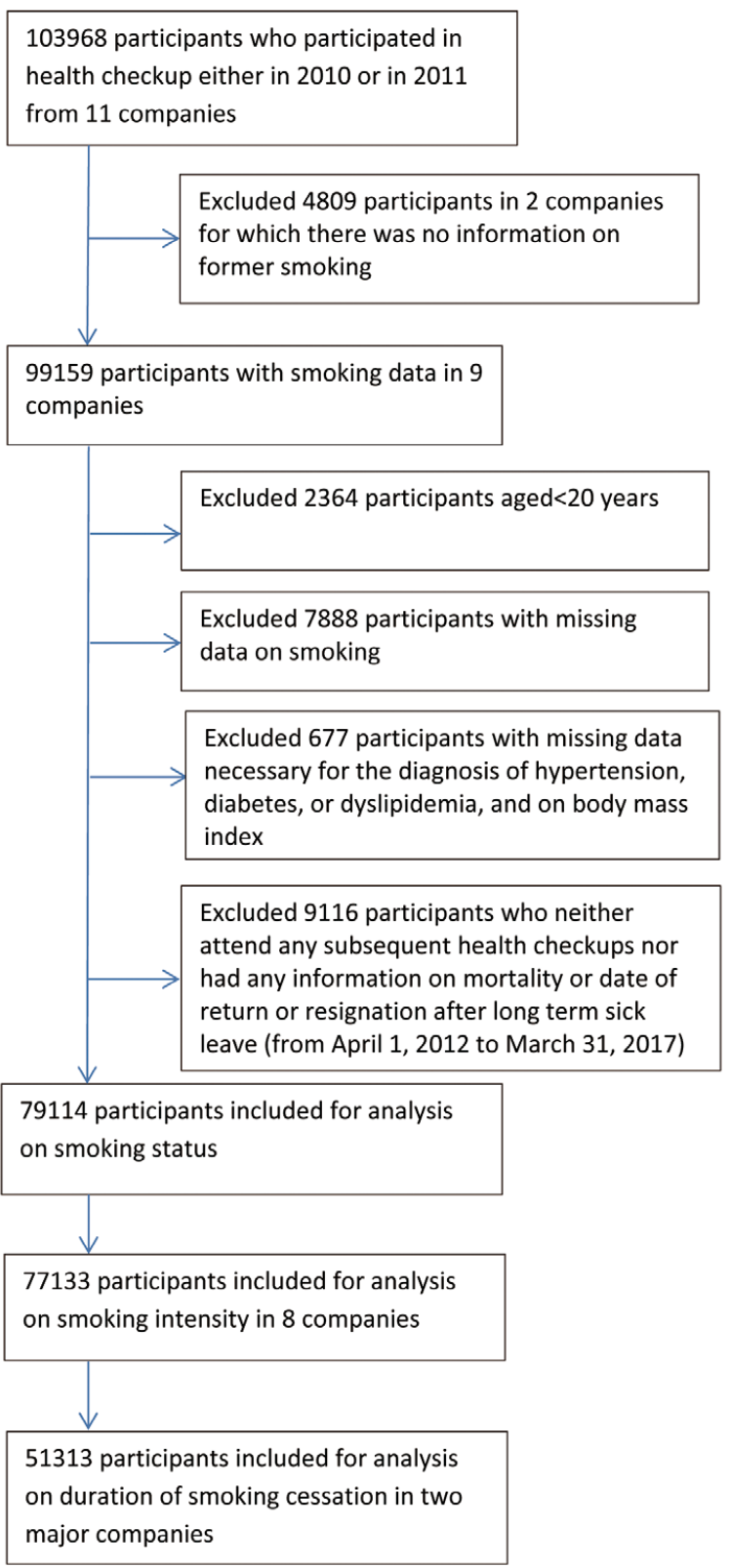

Figure 1. Flow chart of the study population.

cohort studies, $27.8 \%$ and $6.7 \%$ of deaths in Japanese men and women, respectively, can be at least partly attributed to smoking. ${ }^{4}$ Although the prevalence of smoking has decreased in Japan (from $24.2 \%$ in 2006 to $19.6 \%$ in 2016), it remains high, especially among men $(31.7 \%$ in men vs. $9.0 \%$ in women). 5 Among working-age adults (i.e., those aged 20-59 years), the proportion of current smokers among men and women is $38.2 \%$ and $11.6 \%$, respectively. ${ }^{5}$

Despite accumulating evidence demonstrating the harm caused by smoking, ${ }^{2}$ few studies have evaluated the association between smoking and mortality among workingage adults. ${ }^{6-9}$ Of these studies, 2 US studies ${ }^{6,7}$ and 1 Chinese study ${ }^{9}$ conducted long-term follow-up of participants and included the retirement period, whereas another study of Japanese $^{8}$ adults reported an association of smoking with mortality only for all-cause deaths that occurred before retirement. Because the loss of an active and productive member is both socially and economically detrimental to a community, ${ }^{10}$ data collected from working populations are important. However, it remains unknown whether the associations of smoking with all-cause and cause-specific mortality among an active working population would differ from those among retired workers or the general population. Without such epidemiological data, workers may regard the serious consequences of smoking as future (i.e., after retirement) issues, based on a general notion that the majority of smoking-related chronic diseases will occur later in life after a long latency period.

The prevalence of smoking has been steadily decreasing among the Japanese working-age population, ${ }^{11,12}$ due, in part, to the Health Promotion Act, which aimed to implement smoke-free or smoking-restricted workplaces. ${ }^{13}$ Therefore, increased interest has been directed towards determining whether and, if so, when the risk of mortality associated with smoking may decrease after smoking cessation. In previous studies, the relative risk of mortality appeared to decrease at an earlier time point after smoking cessation in the working population ${ }^{68}$ compared with the general population..$^{14,15}$

To further address these issues, the present study examined the associations of smoking, smoking intensity, and smoking cessation with mortality attributed to all causes and specific causes, including cardiovascular disease (CVD), cancer, and other causes, in a large working populationbased cohort study in Japan.

\section{Methods}

\section{Study Design}

The Japan Epidemiology Collaboration on Occupational Health (J-ECOH) Study is an ongoing multicenter epidemiologic study of workers from 12 companies across various industries. In Japan, the Industrial Safety and Health Act obliges workers to undergo health examinations at least once a year; accordingly, nearly all workers undergo an annual health examination. For participants in the J-ECOH Study, anthropometric measurements and laboratory examination data (e.g., blood glucose, blood lipids) were recorded during health examinations. The participants also completed a questionnaire about their medical history, health-related lifestyle, and work environment. The details of the J-ECOH Study have been published previously. ${ }^{16}$ As of May 2016, 11 participating companies (12 worksites) provided health examination data obtained between January 2008 and December 2015 or between April 2008 and March 2016. A mortality registry was set up within the J-ECOH Study in April 2012. For the present cohort analysis, subjects who attended health examinations in either fiscal year 2010 or 2011 were selected. Outcomes were ascertained from April 2012 to March 2017.

Prior to data collection, posters explaining the purpose, procedure, and format of the J-ECOH Study were placed in each participating workplace. The participants did not provide verbal or written informed consent to join the study, but were allowed to refuse to participate. This procedure conformed to the Japanese Ethical Guidelines for Epidemiological Research, which allows simplification of the procedure for obtaining consent in observational studies that use existing data. ${ }^{17}$ The study protocol, 
including the consent procedure, was approved by the Ethics Committee of the National Center for Global Health and Medicine, Japan.

\section{Study Population}

As shown in Figure 1, among the 103,968 participants for whom health check-up data were available during either 2010 or 2011, we excluded subjects from 2 companies $(n=4,809)$ for whom no information about former smoking habits were available. Of the remaining 9 companies $(n=99,159)$, we excluded 2,364 participants aged $<20$ years, 7,888 for whom smoking data were missing, and 677 lacking data necessary for the diagnosis of hypertension, diabetes, or dyslipidemia and body mass index (BMI), which were used in the main analysis. Of the remaining 88,230 participants, we excluded 9,116 who did not attend any subsequent health check-ups and for whom no information about mortality, return, or resignation after long-term sick leave were available. Finally, 79,114 participants were included in our first set of analyses of the association between the risk of mortality among current and former smokers compared with that among never smokers.

Data were available from 8 companies $(n=77,133)$ for the second set of analyses, which assessed the association between smoking intensity among current smokers (number of cigarettes smoked per day) and the risk of mortality. Data were available from 2 major companies $(n=51,313)$ for the third set of analyses that focused on the duration of smoking cessation and risk of mortality.

\section{Assessment of Smoking Status}

In the present study, we used 2010 fiscal year health examination data for the exposure assessment; if data were unavailable during that period, 2011 fiscal year data were used. Smoking status (never, former, or current smoker) was determined from a self-administered questionnaire. Among the 8 companies queried about smoking intensity, participants at 5 companies reported daily cigarette consumption on a continuous scale, whereas those at the other 3 companies were asked to select from among 3 response options $(\leq 10,11-20$, or $\geq 21$ cigarettes per day). Of the 2 companies for which data regarding the duration of smoking cessation were available, participants at one company self-reported years since quitting, whereas participants at the other company self-reported age at quitting. In the latter case, the number of years since quitting was calculated as the age at baseline visit minus the recalled age at quitting.

\section{Ascertainment of Mortality}

Deaths occurring between April 2012 and March 2017 were identified using the within-study registration. Causes of deaths were confirmed from death certificates $(58.7 \%)$, sick leave documents $(20.2 \%)$, family confirmation $(11.5 \%)$, and other sources $(9.6 \%)$, and were classified according to the International Classification of Diseases, 10th revision (ICD-10). The endpoint of the present study was mortality from all causes (total mortality), cancer (ICD-10 Codes C00-C97), CVD (Codes I00-I99), and other causes. For the analysis, we also grouped cancers linked previously with tobacco smoking, namely cancers of the lip, oral cavity, and pharynx (ICD-10 Codes C00-C14), esophagus (Code C15); stomach (Code C16); liver (Code C22); pancreas (Code C25); lung (Codes C33-34); kidney (Code C64); and myeloid leukemia (Code C92). We initially selected tobacco-related cancers based on the 2004 Surgeon General's report. ${ }^{18}$ However, we excluded colorectal cancer according to the recommendations of the Japan Cancer Prevention Group, ${ }^{19}$ which concluded that the level of evidence to support a causal relationship between smoking and colorectal cancer in the Japanese population is "possible" but not "probable" or "convincing".

\section{Assessment of Covariates}

The assessed covariates included age, sex, worksite, BMI, and history of hypertension, diabetes, and dyslipidemia. Body height and weight were measured using a scale while participants wore light clothing without shoes. The BMI was calculated as the weight in kilograms divided by height in meters squared. Blood pressure (BP) was measured using an automatic BP monitor with the participants in a seated position. Plasma glucose was measured using either the enzymatic or glucose oxidase peroxidative electrode method. HbAlc was measured using a latex agglutination immunoassay, HPLC, or the enzymatic method. Triglycerides, low-density lipoprotein cholesterol (LDL-C), and high-density lipoprotein cholesterol (HDL-C) were measured using the enzymatic method. All laboratories involved in the health examinations conducted at the participating companies received satisfactory scores (Rank A or Score $>95 / 100$ ) from external quality control agencies. Hypertension was defined as systolic BP (SBP) $\geq 140 \mathrm{mmHg}$, diastolic BP (DBP) $\geq 90 \mathrm{mmHg}$, or receiving medical treatment for hypertension. Diabetes was defined as HbAlc $\geq 6.5 \%$, fasting plasma glucose (FPG) $\geq 126 \mathrm{mg} / \mathrm{dL}$, random plasma glucose $\geq 200 \mathrm{mg} / \mathrm{dL}$, or currently receiving medical treatment for diabetes in accordance with the American Diabetes Association criteria for the diagnosis of diabetes. ${ }^{20}$ Dyslipidemia was defined as triglycerides $\geq 150 \mathrm{mg} / \mathrm{dL}$, LDL-C $\geq 140 \mathrm{mg} / \mathrm{dL}$, HDL-C $<40 \mathrm{mg} / \mathrm{dL}$, or receiving medical treatment for dyslipidemia in accordance with the criteria of the Japan Atherosclerosis Society. ${ }^{21}$ At one major company, data regarding alcohol consumption and leisure time physical activity were also obtained via a self-administered questionnaire.

\section{Statistical Analyses}

To assess the statistical significance of differences in the background characteristics of the study population across the 3 smoking status categories, continuous and categorical variables were analyzed using analysis of variance (ANOVA) and the Pearson Chi-squared test, respectively.

Person-time was calculated from 31 March 2012 (one day before the beginning of the follow-up period) to the date of death or last examination (whichever occurred first), except for those who required long-term sick leave, for whom the date of return or resignation from work (whichever occurred later) was recorded as the end of follow-up. A Cox proportional hazards model was used to estimate hazard ratios (HRs) of total and cause-specific mortality for each current and former smoker; the never smoker category was used as the reference. Model 1 was adjusted for baseline age (years, continuous), sex, and worksite. Model 2 was additionally adjusted for BMI ( $\mathrm{kg} / \mathrm{m}^{2}$, continuous), hypertension (yes or no), diabetes (yes or no), and dyslipidemia (yes or no). The population attributable fraction (PAF) was calculated using the following formula:

$$
\mathrm{PAF}=\mathrm{pd}[(\mathrm{HR}-1) / \mathrm{HR}]
$$




\begin{tabular}{|c|c|c|c|c|}
\hline & $\begin{array}{c}\text { Never } \\
\text { smokers }\end{array}$ & $\begin{array}{l}\text { Former } \\
\text { smokers }\end{array}$ & $\begin{array}{l}\text { Current } \\
\text { smokers }\end{array}$ & $P$ value \\
\hline No. subjects & 35,973 & 15,784 & 27,357 & \\
\hline Men (\%) & 72.5 & 95.7 & 95.0 & $<0.001$ \\
\hline Age (years) & $40.7 \pm 11.2$ & $46.3 \pm 9.9$ & $42.0 \pm 10.7$ & $<0.001$ \\
\hline $\mathrm{BMI}\left(\mathrm{kg} / \mathrm{m}^{2}\right)$ & $22.9 \pm 3.5$ & $23.8 \pm 3.2$ & $23.5 \pm 3.6$ & $<0.001$ \\
\hline $\mathrm{SBP}(\mathrm{mmHg})$ & $119.8 \pm 14.9$ & $123.4 \pm 14.8$ & $120.9 \pm 14.7$ & $<0.001$ \\
\hline $\mathrm{DBP}(\mathrm{mmHg})$ & $74.1 \pm 11.0$ & $77.9 \pm 10.5$ & $74.9 \pm 10.8$ & $<0.001$ \\
\hline Hypertension (\%) & 15.3 & 25.2 & 17.1 & $<0.001$ \\
\hline Blood glucose (mg/dL) & $97.4 \pm 18.2$ & $102.5 \pm 19.5$ & $100.7 \pm 22.2$ & $<0.001$ \\
\hline $\mathrm{HbA1c}(\%)$ & $5.5 \pm 0.6$ & $5.6 \pm 0.7$ & $5.7 \pm 0.7$ & $<0.001$ \\
\hline Diabetes (\%) & 12.9 & 11.5 & 13.8 & $<0.001$ \\
\hline Triglyceride (mg/dL) & $104.6 \pm 76.8$ & $127.5 \pm 91.3$ & $137.8 \pm 105.9$ & $<0.001$ \\
\hline $\mathrm{HDL}-\mathrm{C}(\mathrm{mg} / \mathrm{dL})$ & $61.7 \pm 15.4$ & $59.4 \pm 14.9$ & $55.0 \pm 13.9$ & $<0.001$ \\
\hline LDL-C (mg/dL) & $117.5 \pm 30.0$ & $121.7 \pm 29.9$ & $119.2 \pm 31.3$ & $<0.001$ \\
\hline Dyslipidemia (\%) & 43.2 & 50.7 & 53.2 & $<0.001$ \\
\hline
\end{tabular}

Unless indicated otherwise, data are given as the mean \pm SD or as percentages. $P$ values were calculated using the Pearson Chi-squared test for categorical variables or analysis of variance $\mathrm{F}$-test for continuous variables at baseline. BMI, body mass index; DBP, diastolic blood pressure; HDL-C, high-density lipoprotein cholesterol; LDL-C, low density lipoprotein cholesterol; SBP, systolic blood pressure.

where pd is the proportion of cases exposed to the risk factor and HR is the adjusted HR in Model $2 .{ }^{22}$

We also conducted several sensitivity analyses to evaluate the consistency of our results. To restrict our analysis, we excluded 1,540 subjects with self-reported histories of CVD and cancer because these chronic diseases affect mortality and may affect smoking status. In one company $(n=39,498)$ in which detailed information about lifestyle variables was available, we added alcohol intake $(<23$ or $\geq 23 \mathrm{~g}$ ethanol/day) and physical activity ( $<150$ or $\geq 150 \mathrm{~min} /$ week) to Model 2. For the smoking assessment, we also used 2008 health examination data to evaluate potential changes in smoking behavior attributable to episodes of illness, especially among cases of death during the follow-up period.

We further estimated the multivariable-adjusted HRs for total and cause-specific mortality according to smoking intensity among smokers who smoked 1-10, 11-20, and $\geq 21$ cigarettes per day, compared with people who never smoked. Tests for trends were performed by assigning ordinal numbers to the smoking intensity categories and modeling this parameter as a continuous variable. To assess the effects of smoking cessation on the risk of total mortality, we stratified the study population into 4 smoking categories: never smokers, former smokers who had quit $<5$ or $\geq 5$ years before baseline, and current smokers. All analyses were performed using Stata version 14 (StataCorp, College Station, TX, USA).

\section{Results}

Compared with participants included in the present study $(n=79,114)$, those who were excluded due to the lack of any follow-up data $(n=9,116)$ were older, tended to be current smokers, and had higher mean BMI, SBP, DBP, FPG, and HbAlc.

Table 1 lists the characteristics of the study population by smoking status. The prevalence rates of current and former smoking at baseline were $34.6 \%$ and $20.0 \%$, respectively. Former smokers were older, had higher mean BMI,
SBP, DBP, blood glucose, and LDL-C, and a higher prevalence of hypertension relative to their counterparts. Current smokers had higher mean triglyceride concentrations and higher prevalence rates of dyslipidemia and diabetes, but lower mean HDL-C concentrations compared with never smokers and former smokers.

Table 2 shows the adjusted HRs (aHRs) for total and cause-specific mortality according to baseline smoking status. During a maximum 6 years of follow-up, 252, 108, 63 , and 81 deaths were attributed to all causes, cancer, CVD, and other causes, respectively. After adjusting for age, sex, worksite, BMI, hypertension, diabetes, and dyslipidemia, the aHRs and $95 \%$ confidence intervals (CIs) for total mortality were $1.27(0.90-1.78)$ in former smokers and 1.49 (1.10-2.01) in current smokers compared with never smokers. The corresponding values were 1.49 (0.91$2.45)$ and $1.35(0.83-2.18)$ for cancer mortality, $1.79(0.98-$ $3.26)$ and $1.80(1.02-3.19)$ for tobacco-related cancer mortality, $0.93(0.44-1.97)$ and $1.79(0.99-3.24)$ for CVD mortality, and $1.30(0.71-2.40)$ and $1.50(0.89-2.50)$ for other cause mortality. In addition, the PAFs of total mortality attributed to current and former smoking were $13.7 \%$ and $5.5 \%$, respectively, with corresponding values of $9.1 \%$ and $10.3 \%$ for cancer mortality and $14.5 \%$ and $18.0 \%$ for tobacco-related cancer mortality. The PAFs of CVD and other-cause mortality attributed to current smoking were $21.7 \%$ and $14.8 \%$, respectively (Table 2 ).

We subsequently excluded subjects with histories of cancer and CVD at baseline from the analyses and observed a similar association. Specifically, the risks of total mortality, cancer mortality, and CVD mortality among current smokers relative to never smokers were 1.53 (1.12-2.11), $1.53(0.91-2.58)$, and $1.78(0.95-3.36)$, respectively. In addition, similar results were obtained in an analysis of one company for which detailed lifestyle data were available. After further adjustment for alcohol intake and physical activity, the aHRs $(95 \% \mathrm{CI})$ for total, cancer, and CVD mortality among current smokers relative to never smokers were 1.59 (1.00-2.54), $1.72(0.80-3.36)$, and 1.67 (0.71-3.89), respectively. These results were virtually unchanged when 


\begin{tabular}{|c|c|c|c|}
\hline & \multicolumn{3}{|c|}{ Baseline smoking status } \\
\hline & Never smoker & Former smoker & Current smoker \\
\hline No. subjects & 35,973 & 15,784 & 27,357 \\
\hline Person-years & 154,600 & 65,462 & 117,418 \\
\hline \multicolumn{4}{|l|}{ Total mortality } \\
\hline No. deaths & 82 & 65 & 105 \\
\hline Model 1 aHR $(95 \% \mathrm{Cl})$ & 1.00 (Ref.) & $1.28(0.91-1.80)$ & $1.48(1.10-2.00)$ \\
\hline Model 2 aHR $(95 \% \mathrm{Cl})$ & 1.00 (Ref.) & $1.27(0.90-1.78)$ & $1.49(1.10-2.01)$ \\
\hline PAF (\%) & - & 5.5 & 13.7 \\
\hline \multicolumn{4}{|l|}{ All-cancer mortality } \\
\hline No. deaths & 36 & 34 & 38 \\
\hline Model 1 aHR $(95 \% \mathrm{Cl})$ & 1.00 (Ref.) & $1.49(0.91-2.46)$ & $1.34(0.83-2.16)$ \\
\hline Model 2 aHR $(95 \% \mathrm{Cl})$ & 1.00 (Ref.) & $1.49(0.91-2.45)$ & $1.35(0.83-2.18)$ \\
\hline PAF (\%) & - & 9.1 & 10.3 \\
\hline \multicolumn{4}{|c|}{ Tobacco-related cancer mortality ${ }^{A}$} \\
\hline No. deaths & 21 & 26 & 32 \\
\hline Model 1 aHR $(95 \% \mathrm{Cl})$ & 1.00 (Ref.) & $1.79(0.98-3.27)$ & $1.78(1.00-3.15)$ \\
\hline Model 2 aHR $(95 \% \mathrm{Cl})$ & 1.00 (Ref.) & $1.79(0.98-3.26)$ & $1.80(1.02-3.19)$ \\
\hline PAF (\%) & - & 14.5 & 18.0 \\
\hline \multicolumn{4}{|l|}{ CVD mortality } \\
\hline No. deaths & 20 & 12 & 31 \\
\hline Model 1 aHR $(95 \% \mathrm{Cl})$ & 1.00 (Ref.) & $0.98(0.46-2.06)$ & $1.85(1.02-3.34)$ \\
\hline Model 2 aHR $(95 \% \mathrm{Cl})$ & 1.00 (Ref.) & $0.93(0.44-1.97)$ & $1.79(0.99-3.24)$ \\
\hline PAF (\%) & - & - & 21.7 \\
\hline \multicolumn{4}{|l|}{ Other cause mortality } \\
\hline No. deaths & 26 & 19 & 36 \\
\hline Model 1 aHR $(95 \% \mathrm{Cl})$ & 1.00 (Ref.) & $1.29(0.70-2.37)$ & $1.47(0.88-2.45)$ \\
\hline Model 2 aHR $(95 \% \mathrm{Cl})$ & 1.00 (Ref.) & $1.30(0.71-2.40)$ & $1.50(0.89-2.50)$ \\
\hline PAF (\%) & - & 5.4 & 14.8 \\
\hline
\end{tabular}

ATobacco-related cancers were selected according to the Surgeon General's Report of $2004^{18}$ and the Japan Cancer Prevention Group evaluation of cancer risk factors. ${ }^{19}$ Model 1 was adjusted for age (years), sex, and worksite. Model 2 was adjusted for all factors in Model 1 plus BMI $\left(\mathrm{kg} / \mathrm{m}^{2}\right)$, hypertension (yes or no), diabetes (yes or no), and dyslipidemia (yes or no). The population attributable fraction (PAF) was calculated as follows: $P A F=p d[(H R-1) / H R]$, where pd is the proportion of cases exposed to the risk factor and HR is the adjusted hazard ratio in Model 2. aHR, adjusted hazard ratio; $\mathrm{BMI}$, body mass index; $\mathrm{Cl}$, confidence interval; CVD, cardiovascular disease.

2008 fiscal year health examination data were used for the exposure assessment (data not shown).

Table 3 presents the risks of mortality according to the baseline smoking intensity. The risk of total mortality was significantly higher among those who consumed $\geq 21$ cigarettes per day compared with never smokers (aHR 2.24; $95 \%$ CI 1.43-3.51). The risk of cancer mortality increased as the number of cigarettes smoked per day increased, although this trend was not significant. In contrast, a clear dose-response relationship was observed between smoking intensity and tobacco-related cancer mortality, with aHRs (95\% CIs) of 1.55 (0.58-4.14), 1.64 (0.85-3.16), and 2.31 (1.02-5.26) among people who smoked 1-10, 11-20, and $\geq 21$ cigarettes per day, respectively, compared with never smokers $\left(P_{\text {trend }}=0.03\right)$. The aHRs $(95 \%$ CIs $)$ for CVD were $1.64(0.60-4.48), 1.81(0.90-3.65)$, and 2.45 (1.01-5.91) among people who smoked $1-10,11-20$, and $\geq 21$ cigarettes per day, respectively $\left(P_{\text {trend }}=0.03\right)$, whereas for other cause mortality the corresponding aHRs (95\% CIs) were 2.26 (1.10-4.64), 1.06 (0.55-2.05), and 2.78 (1.28-6.01; $P$ trend $=0.08)$.

Figure 2 shows the HRs for total mortality by years since quitting before baseline. In the multivariable adjusted model, the HRs $(95 \%$ CIs) for total mortality were 1.00 (reference), 1.80 (1.00-3.25), and $1.02(0.57-1.82)$ for never smokers and former smokers who had quit $<5$ years and $\geq 5$ years before the baseline visit, respectively.

\section{Discussion}

In a study based on a large database of Japanese workers, we identified associations of cigarette smoking with increased risks of total and tobacco-related cancer mortality. We also found that smoking was associated with higher risks of mortality associated with specific causes, including total cancer, CVD, and other causes, although these latter associations were not statistically significant. Among current smokers, the risks of total, tobacco-related cancer, and CVD mortality increased significantly as smoking intensity increased, whereas the elevated risk for total mortality associated with smoking disappeared after 5 years of smoking cessation. Current smoking accounted for $13.7 \%, 21.7 \%$, and $18.0 \%$ of total, CVD, and tobaccorelated cancer mortality events, respectively. To our knowledge, the present study is among the few studies to investigate the association between smoking and the risk 


\begin{tabular}{|c|c|c|c|c|}
\hline & No. subjects & No. deaths & $\begin{array}{c}\text { Model } 1 \text { aHR } \\
(95 \% \mathrm{Cl})\end{array}$ & $\begin{array}{l}\text { Model } 2 \text { aHR } \\
\quad(95 \% \mathrm{Cl})\end{array}$ \\
\hline \multicolumn{5}{|l|}{ Total mortality } \\
\hline Never smoker & 35,384 & 79 & 1.00 (Ref.) & 1.00 (Ref.) \\
\hline \multicolumn{5}{|c|}{ Current smoker (cigarettes smoked/day) } \\
\hline $1-10$ & 6,268 & 22 & $1.67(1.04-2.70)$ & $1.68(1.04-2.71)$ \\
\hline $11-20$ & 16,227 & 53 & $1.29(0.90-1.86)$ & $1.29(0.89-1.86)$ \\
\hline$\geq 21$ & 3,922 & 29 & $2.32(1.48-3.64)$ & $2.24(1.43-3.51)$ \\
\hline$P_{\text {trend }}$ & & & 0.002 & 0.002 \\
\hline \multicolumn{5}{|c|}{ All-cancer mortality } \\
\hline Never smoker & 35,384 & 36 & 1.00 (Ref.) & 1.00 (Ref.) \\
\hline \multicolumn{5}{|c|}{ Current smoker (cigarettes smoked/day) } \\
\hline $1-10$ & 6,268 & 6 & $1.16(0.48-2.78)$ & $1.16(0.48-2.77)$ \\
\hline $11-20$ & 16,227 & 21 & $1.25(0.71-2.22)$ & $1.26(0.71-2.22)$ \\
\hline$\geq 21$ & 3,922 & 11 & $1.89(0.92-3.86)$ & $1.89(0.92-3.86)$ \\
\hline$P_{\text {trend }}$ & & & 0.12 & 0.13 \\
\hline \multicolumn{5}{|c|}{ Tobacco-related cancer mortality } \\
\hline Never smoker & 35,384 & 21 & 1.00 (Ref.) & 1.00 (Ref.) \\
\hline \multicolumn{5}{|c|}{ Current smoker (cigarettes smoked/day) } \\
\hline $1-10$ & 6,268 & 5 & $1.54(0.58-4.11)$ & $1.55(0.58-4.14)$ \\
\hline $11-20$ & 16,227 & 18 & $1.63(0.84-3.15)$ & $1.64(0.85-3.16)$ \\
\hline$\geq 21$ & 3,922 & 9 & $2.33(1.03-5.29)$ & $2.31(1.02-5.26)$ \\
\hline$P_{\text {trend }}$ & & & 0.03 & 0.03 \\
\hline \multicolumn{5}{|l|}{ CVD mortality } \\
\hline Never smoker & 35,384 & 19 & 1.00 (Ref.) & 1.00 (Ref.) \\
\hline \multicolumn{5}{|c|}{ Current smoker (cigarettes smoked/day) } \\
\hline $1-10$ & 6,268 & 5 & $1.64(0.60-4.45)$ & $1.64(0.60-4.48)$ \\
\hline $11-20$ & 16,227 & 17 & $1.83(0.91-3.67)$ & $1.81(0.90-3.65)$ \\
\hline$\geq 21$ & 3,922 & 7 & $2.69(1.12-6.49)$ & $2.45(1.01-5.91)$ \\
\hline$P_{\text {trend }}$ & & & 0.02 & 0.03 \\
\hline \multicolumn{5}{|c|}{ Other-cause mortality } \\
\hline Never smoker & 35,384 & 24 & 1.00 (Ref.) & 1.00 (Ref.) \\
\hline \multicolumn{5}{|c|}{ Current smoker (cigarettes smoked/day) } \\
\hline $1-10$ & 6,268 & 11 & $2.25(1.10-4.63)$ & $2.26(1.10-4.64)$ \\
\hline $11-20$ & 16,227 & 15 & $1.06(0.55-2.05)$ & $1.06(0.55-2.05)$ \\
\hline$\geq 21$ & 3,922 & 10 & $2.86(1.33-6.16)$ & $2.78(1.28-6.01)$ \\
\hline$P_{\text {trend }}$ & & & 0.07 & 0.08 \\
\hline
\end{tabular}

AAnalyses excluded former smokers ( $n=13,488)$. Model 1 was adjusted for age (years), sex, and worksite. Model 2 was adjusted for all factors in Model 1 plus BMI ( $\mathrm{kg} / \mathrm{m}^{2}$ ), hypertension (yes or no), diabetes (yes or no), and dyslipidemia (yes or no). Abbreviations as in Table 2.

of mortality in a working population.

In the present study, current smoking was associated with a 1.49-fold increased risk of total mortality. This estimate was comparable to the risks reported in a previous Japanese study conducted in a working population (HR $\sim 1.5)^{8}$ and in the general Japanese population (HRs 1.60 1.89).,423,24 The total mortality rate in the present study was also compatible with a previous pooled analysis of 21 cohorts from community-based Asian populations. ${ }^{25} \mathrm{We}$ also identified strong associations of smoking with CVD and tobacco-related cancer mortality (HRs 1.79 and 2.33, respectively), which were consistent with previous studies in a general Japanese population (HRs 1.52 for men and 1.98 for women for CVD, and 2.32 for men and 2.01 for women for tobacco-related cancer $)^{4}$ and an Asian population (HR, 1.35 for men and 1.54 for women for CVD). ${ }^{25}$ The lack of a material difference in the association (in terms of relative risk) of smoking with mortality between the active working and non-working populations suggests that workers should be advised to avoid smoking to prevent and/or delay premature deaths (i.e., those occurring before retirement).

Among current smokers, we observed clear doseresponse relationships of smoking intensity with CVD and tobacco-related cancer mortality. In addition, participants who smoked $\geq 21$ cigarettes per day had significantly increased risks of all-cause and other cause mortality. Previously, 2 studies conducted in US working populations, ${ }^{7,26}$ followed for more than 20 years during their lifetimes identified clear dose-response relationships between smoking and all-cause and cause-specific mortality (including CVD and cancer). Conversely, a prospective study of current Japanese workers who were followed for 7.5 years found that heavy smoking ( $\geq 21$ cigarettes per day) was not significantly associated with an increased risk of mortality (HR 1.30; 95\% CI $0.70-2.31$ ). ${ }^{8}$ However, the relatively 


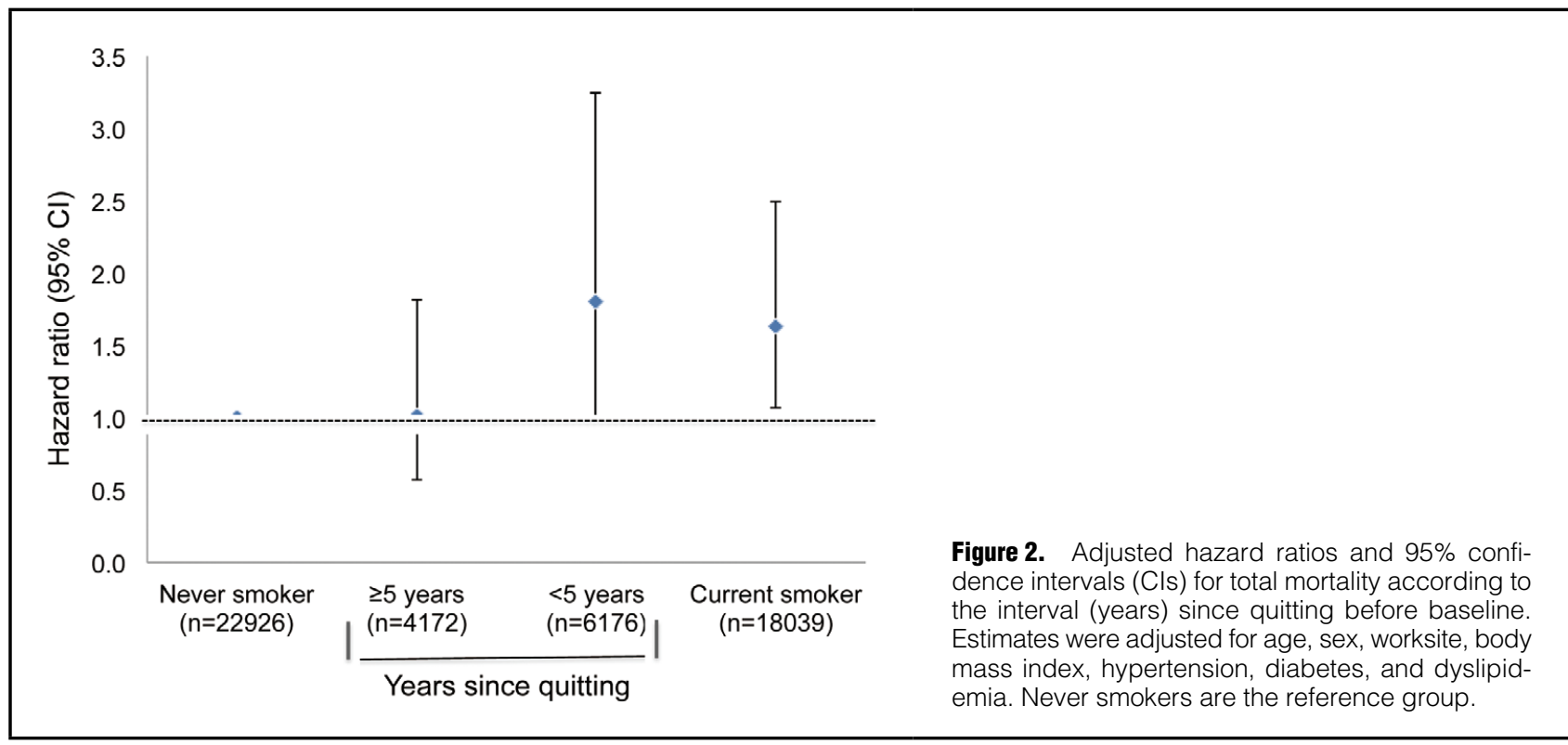

smaller number of subjects $(n=25,464)$ and small number of deaths in the heavy smoking category $(n=19)$ suggests that the latter study may have been underpowered to detect a significant dose-response relationship. ${ }^{\mathbf{8}}$ In contrast, the present study included a greater number of subjects and therefore provides clearer evidence to support the associations of cigarette smoking with increased risks of total and cause-specific mortality (including CVD and tobacco-related cancer mortality) in a dose-response manner among active workers.

We further observed that participants who quit smoking $<5$ years before baseline had a significantly increased risk of total mortality compared with never smokers, and a slightly higher risk than that of current smokers. However, those who quit $\geq 5$ years before baseline had a decreased risk of mortality, and the risk decreased to the level observed among non-smokers. In a previous study of Japanese workers, ${ }^{8}$ the risk of mortality decreased by $43 \%$ among those who quit smoking $\geq 4$ years before baseline compared with current smokers, and the Physicians' Health Study ${ }^{6}$ and Nurses' Health Study ${ }^{7}$ reported that previous smokers who had quit smoking $<5$ years before baseline had a lower risk of mortality compared with current smokers (decreases in relative risk of approximately $35 \%$ and $13 \%$, respectively). In contrast, previous studies of middle-aged or older general populations found that the risk of mortality remained relatively high (vs. never smokers), even 10 years after quitting. ${ }^{\mathbf{1 4 , 1 5 , 2 3}}$ The more rapid reduction in mortality risk after smoking cessation among workers relative to the general public may be attributable to a younger age at the time of smoking cessation in the former group. Another study reported that the risk of mortality decreased more rapidly among ever smokers who stopped smoking at a younger age $(<50$ years) compared with those who stopped at an older age. ${ }^{27}$ Together, these data indicate a larger and more rapid effect of smoking cessation on mortality prevention (in terms of relative risk) among the working population compared with the general population.

The strengths of the present study included its prospective design, large sample size, and use of data from multiple companies. Despite these strengths, the present study has several limitations that should be noted. First, because we did not collect data on diet or lifestyle factors (e.g., alcohol consumption and physical activity) in a standardized manner across the participating companies, we were unable to control for the effects of these confounders. However, we obtained similar findings after additionally adjusting our analyses for alcohol consumption and physical activity, because data for these factors were available in one major company. Second, exposure to passive smoking has been linked to an increase in the risk for all-cause mortality, CVD, and certain cancers. ${ }^{28}$ Given that we have no information on exposure to passive smoking among non-smokers, the present risk estimate for the association between smoking and mortality may have been underestimated. Third, the participants may have quit or reduced tobacco smoking because of illness; however, we confirmed that the results of our analyses were materially unchanged after excluding subjects with a history of cancer and CVD. Fourth, the study included few cases of cause-specific mortality, and therefore the statistical power may not have been sufficient to detect a statistically significant association. Fifth, approximately $10 \%$ of participants who were excluded from the present analysis for not attending any subsequent health check-ups tended to be current smoker and they might have a higher risk of mortality. Thus, we cannot deny the possibility of bias associated with such selective inclusion. Finally, the study subjects were employed at large companies, and thus the findings may not be generalizable to smaller companies or workers with different backgrounds.

In conclusion, the present study, which was based on a large-scale cohort of Japanese workers, identified dosedependent associations of smoking with increased risks of total mortality, CVD mortality, and tobacco-related cancer mortality. Former smokers who had quit smoking within 5 years had a higher risk of mortality than never smokers, although the increased risk in the former group decreased to the level for non-smokers beyond 5 years after 
smoking cessation. These findings strongly confirm the benefits of smoking cessation in the working population and provide a rationale for the urgent implementation of tobacco control programs, especially in countries such as Japan, where tobacco smoking remains prevalent. Antismoking programs in the workplace should be designed to improve the health of both non-smokers and smokers by eliminating passive smoking and helping people to quit smoking, respectively.

\section{Acknowledgments}

The authors thank Toshiteru Okubo (Chairperson, Industrial Health Foundation) for scientific advice on conducting the J-ECOH Study, and Rika Osawa (National Center for Global Health and Medicine) for administrative support.

\section{Sources of Funding}

This study was supported by the Industrial Health Foundation, Industrial Disease Clinical Research Grants (140202-01, 150903-01, 170301-01), the Japan Society for the Promotion of Science KAKENHI (16H05251), and a grant from the National Center for Global Health and Medicine (28-Shi-1206).

\section{Conflict of Interest}

The authors declare no conflicts of interest.

\section{References}

1. Gellert C, Schottker B, Brenner H. Smoking and all-cause mortality in older people: Systematic review and meta-analysis. Arch Intern Med 2012; 172: 837-844.

2. The health consequences of smoking - 50 years of progress: A report of the Surgeon General. Atlanta, GA; 2014. https://www. surgeongeneral.gov/library/reports/50-years-of-progress/index. html (accessed August 9, 2018).

3. World Health Organization. WHO global report: Mortality attributable to tobacco. 2012. http://www.who.int/tobacco/ publications/surveillance/rep_mortality_attributable/en/ (accessed August 9, 2018).

4. Katanoda K, Marugame T, Saika K, Satoh H, Tajima K, Suzuki $\mathrm{T}$, et al. Population attributable fraction of mortality associated with tobacco smoking in Japan: A pooled analysis of three large-scale cohort studies. J Epidemiol 2008; 18: 251-264.

5. Japan Ministry of Health Labour and Welfare. Annual reports of the National Health and Nutrition Survey in Japan, 2016. Tokyo: Daiichi-shuppan; 2017 (in Japanese).

6. Cao Y, Kenfield S, Song Y, Rosner B, Qiu W, Sesso HD, et al. Cigarette smoking cessation and total and cause-specific mortality: A 22-year follow-up study among US male physicians. Arch Intern Med 2011; 171: 1956-1959.

7. Kenfield SA, Stampfer MJ, Rosner BA, Colditz GA. Smoking and smoking cessation in relation to mortality in women. $J A M A$ 2008; 299: 2037-2047.

8. Kondo T, Osugi S, Shimokata K, Honjo H, Morita Y, Maeda $\mathrm{K}$, et al. Smoking and smoking cessation in relation to all-cause mortality and cardiovascular events in 25,464 healthy male Japanese workers. Circ J 2011; 75: 2885-2892.

9. He Y, Jiang B, Li LS, Li LS, Sun DL, Wu L, et al. Changes in smoking behavior and subsequent mortality risk during a 35-year follow-up of a cohort in Xi'an, China. Am J Epidemiol 2014; 179: $1060-1070$

10. Ekpu VU, Brown AK. The economic impact of smoking and of reducing smoking prevalence: Review of evidence. Tob Use Insights 2015; 8: 1-35.

11. Higashibata T, Nakagawa H, Okada R, Wakai K, Hamajima N. Trends in smoking rates among urban civil servants in Japan according to occupational categories. Nagoya J Med Sci 2015; 77: $417-423$.

12. Wada K, Higuchi Y, Smith DR. Assessing the impact of nationwide smoking cessation interventions among employed, middle-aged Japanese men, 2005-2010. PLoS One 2016; 11: $\mathrm{e} 0155151$.

13. Tobacco control laws. Legislation by country: Japan. http:// www.tobaccocontrollaws.org/legislation/country/japan/laws (accessed March 15, 2018).

14. Jamrozik K, McLaughlin D, McCaul K, Almeida OP, Wong KY, Vagenas D, et al. Women who smoke like men die like men who smoke: Findings from two Australian cohort studies. Tob Control 2011; 20: 258-265.

15. LaCroix AZ, Lang J, Scherr P, Wallace RB, Cornoni-Huntley J, Berkman L, et al. Smoking and mortality among older men and women in three communities. N Engl J Med 1991; 324: 16191625 .

16. Akter S, Okazaki H, Kuwahara K, Miyamoto T, Murakami T, Shimizu C, et al. Smoking, smoking cessation, and the risk of type 2 diabetes among Japanese adults: Japan Epidemiology Collaboration on Occupational Health Study. PLoS One 2015; 10: $\mathrm{e} 0132166$.

17. Ministry of Health, Labour and Welfare. Ethical guidelines for epidemiological research. Tokyo: Ministry of Health, Labour and Welfare; 2000.

18. Office of the Surgeon General (US), Office on Smoking and Health (US). The health consequences of smoking: A report of the Surgeon General. Atlanta GA: Centers for Disease Control and Prevention (US); 2004.

19. National Cancer Center. Development and evaluation of cancer prevention strategies in Japan. http://epi.ncc.go.jp/cgi-bin/cms/ public/index.cgi/nccepi/en/can_prev/outcome/index (accessed February 25, 2018).

20. American Diabetes Association. Classification and diagnosis of diabetes. Diabetes Care 2017; 40(Suppl 1): S11-S24.

21. Teramoto T, Sasaki J, Ishibashi S, Birou S, Daida H, Dohi S, et al. Executive summary of the Japan Atherosclerosis Society Guidelines for the diagnosis and prevention of atherosclerotic cardiovascular diseases in Japan - 2012 version. J Atherosclerosis Thromb 2013; 20: 517-523.

22. Rockhill B, Newman B, Weinberg C. Use and misuse of population attributable fractions. Am J Public Health 1998; 88: $15-19$

23. Ozasa K. Smoking and mortality in the Japan collaborative cohort study for evaluation of cancer (JACC). Asian Pac J Cancer Prev 2007; 8(Suppl): 89-96.

24. Sakata R, McGale P, Grant EJ, Ozasa K, Peto R, Darby SC. Impact of smoking on mortality and life expectancy in Japanese smokers: A prospective cohort study. BMJ 2012; 345: e7093.

25. Zheng W, McLerran DF, Rolland BA, Fu Z, Boffetta P, He J, et al. Burden of total and cause-specific mortality related to tobacco smoking among adults aged $\geq 45$ years in Asia: A pooled analysis of 21 cohorts. PLoS Med 2014; 11: e1001631.

26. Doll R, Peto R, Boreham J, Sutherland I. Mortality in relation to smoking: 50 years' observations on male british doctors. $B M J$ 2004; 328: 1519 .

27. Taylor DH Jr, Hasselblad V, Henley SJ, Thun MJ, Sloan FA. Benefits of smoking cessation for longevity. Am J Public Health 2002; 92: 990-996.

28. Lv X, Sun J, Bi Y, Xu M, Lu J, Zhao L, et al. Risk of all-cause mortality and cardiovascular disease associated with secondhand smoke exposure: A systematic review and meta-analysis. Int $J$ Cardiol 2015; 199: 106-115. 